\title{
Type 1 diabetes mellitus: therapeutic correction trial with the aqueous extract of the leaves of Tapinanthus dodoneifolius (Loranthaceae)
}

\author{
Kopodjing Bello Angèle ${ }^{1 *}$, Ntchapda Fidèle ${ }^{1}$ and Miaffo David ${ }^{2}$ \\ ${ }^{1}$ Laboratory of Medicinal Plants, Health and Galenic Formulation, \\ Department of Biological Sciences, Faculty of Sciences, University of Ngaoundere, \\ P.O. Box 454 Ngaoundere, Cameroon \\ ${ }^{2}$ Laboratory of Life and Earth Sciences, Department of Life and Earth Sciences, Higher \\ Teachers' Training College, University of Maroua, P.O. Box 55 Maroua, Cameroon \\ *Corresponding author
}

\section{A B S T R A C T}

\section{Keywords}

Tapinanthus dodoneifolius, lipid profile, antioxidant potential, diabetes mellitus, streptozotocin

Article Info

\section{Accepted:}

20 June 2021

Available Online:

10 July 2021
Tapinanthus dodoneifolius (Loranthaceae) is an epiphytic parasitic plant used in the treatment of cholera, asthma, hypertension, and diabetes. The general objective of this study was to evaluate the antidiabetic properties of the aqueous extract of the leaves of T. dodoneifolius (Loranthaceae) in the Wistar rat. Type 1 diabetes was induced by intraperitoneal injection of streptozotocin into the single dose of $60 \mathrm{mg} / \mathrm{kg}$. Seventytwo hours later, rats with blood glucose $\geq 200 \mathrm{mg} / \mathrm{dL}$ were selected and treated for 28 days with distilled water, glibenclamide $(3 \mathrm{mg} / \mathrm{kg})$ and aqueous extract of T.dodoneifolius at doses of 125, 250 and $500 \mathrm{mg} / \mathrm{kg}$. Body weight, blood sugar, and food and water intake were measured during treatment. At the end of treatment, serum insulin level, lipid profile and oxidative stress parameters were assessed. Results showed that administration of the extract of $T$. dodoneifolius leaves at doses of 250 and / or $500 \mathrm{mg} / \mathrm{kg}$ prevented drastic loss of body weight and reduced food and water consumption in diabetic rats. Blood glucose, TC, TG, LDL-c, and MDA were also reduced and HDL-c, GSH, and CAT and SOD activity increased after administration of the extract of $T$. dodoneifolius ( 250 and $500 \mathrm{mg} / \mathrm{kg}$ ) in diabetic rats. At the end of this work, it appears that the aqueous extract of the leaves of $T$. dodoneifolius has antidiabetic, lipid-lowering, and antioxidant properties, thus supporting the use of this plant by traditional healers for the treatment of diabetes and some of its complications.

\section{Introduction}

Diabetes mellitus is a chronic metabolic disease that occurs when fasting glycaemia greater than or equal to $126 \mathrm{mg} / \mathrm{mL}$ (American Diabetes Association, 2010). It represents a real public health problem in the world. In fact, more than 425 million people suffered from diabetes in 2017 (ADA, 2010). This number is projected to almost double by 2030 (International Diabetes Federation, 2019). According to estimates by the World Health 
Organization, diabetes could become the seventh leading cause of death in the world by 2030. Type 1 diabetes is characterized by the destruction of the $\beta$ cells in the pancreas that produce insulin. It most often occurs before the age of 20 and accounts for 10 to $15 \%$ of diabetes mellitus. Uncontrolled permanent hyperglycemia can lead to long-term production of reactive oxygen species and damage to organs such as the eyes, nerves, kidneys and blood vessels (Standards of Medical Care in Diabetes, 2016).

The treatment of diabetes is based on strict diet, oral medication, and daily injection of insulin.

Daily injections of insulin requires a large financial means. Moreover, the choice of oral antidiabetic drugs depends on the patient's profile, lifestyle, level of glycemic control, access to medication and economic status. Due to these many limitations, the potential of natural products for the treatment of metabolic syndrome-related disorders is under exploration. Numerous plant extracts have been used in traditional folk medicine to treat hyperglycemia Efuntoye et al., 2010). Tapinanthus dodoneifolius DC Danser (Loranthaceae) is extensively used as medicinal plant in traditional medicine in Africa in the treatment of malaria, hypertension, cholera, asthma, epilepsy, cancer, and diabetes (Ekhaise et al., 2010 ; Nasri and Rafieian-Kopaei, 2014). Phytochemical screening showed the presence of anthraquinones, saponins, flavonoids, alkaloids, and tannins from Tapinanthus dodoneifolius(Deeni and Sadiq, 2002; Ekhaise et al., 2010 ; Baso and Mudi, 2017). However, very limited information is available on in vivo antidiabetic, antidyslipidaemic, antioxidant activities of $T$. dodoneifolius. Thus, the aim of this study was to contribute to the valuation of $T$. dodoneifoliusin the treatment of diabetes mellitus and its complications.

\section{Materials and Methods}

\section{Chemicals and reagents}

Glibenclamide, metformin, potassium dichromate, ketamine and diazepam were bought at the pharmacy in the Far North region, Cameroon. Streptozotocin, rat insulin ELISA and biochemical kits were purchased from Sigma-Aldrich, Saint. Louis, USA.Dglucose and sodium chloride were purchased from Edu-Lab Biology Kit, Bexwell, Norfolk PE38 9GA, UK. All chemicals and drugs were obtained commercially in analytical grade.

\section{Harvest and identification of plant material}

Fresh leaves of Tapinanthus dodoneifolius were collected from Kaélé, Cameroon, in July 2018. A sample of the plant has been identified and authenticated in the National Herbarium of Cameroon under the number 6925NHC. Subsequently, the collected leaves were washed with tap water, dried at room temperature, and then crushed to obtain the powder.

\section{Preparation of the extract}

Seventy five gram (75) of powder of $T$. dodoneifolius were introduced into $500 \mathrm{~mL}$ of distilled water previously brought to the boil. After $30 \mathrm{~min}$, the resulting infusion was filtered using No. 1 filter paper and the filtrate was evaporated in an oven at $45^{\circ} \mathrm{C}$ for 48 hours. This allowed us to obtain $13.6 \mathrm{~g}$ of crude extract with an extraction yield of $4.53 \%$.

\section{Phytochemical screening}

Phytochemical screening was carried out for aqueous extract of $T$. dodoneifolius leaves using standard procedures to determine the presence of phenols, flavonoids, tannins, alkaloids, anthraquinones, terpenoids, 
saponins, glycosides, alkaloids, and steroids (Pandey and Tripathi, 2014).

\section{Animal material}

Male albino Wistar rats aged 8 to 12 weeks and weighing between $150 \mathrm{~g}$ and $250 \mathrm{~g}$ were used in the experiment. They were provided by the animal house of the Department of Biological Sciences at the University of Ngaoundere (Cameroon).

All the animals were placed in polypropylene cages at room temperature with a 12/12 h cycle (light/dark). They had free access to water and standard diet. They were acclimatized for 1 week prior to experimentation. The experimental protocols were conducted in accordance with internationally accepted principles for laboratory animal use and were approved the Institutional Animal Ethics Committee (IAEC).

\section{Induction of diabetes}

After a 24-hour non-water fast, diabetes was induced in rats by the intraperitoneal injection of a single dose $(55 \mathrm{mg} / \mathrm{kg}$ body weight) of streptozotocin diluted in citrate buffer $(0.1$ $\mathrm{mol} / \mathrm{L}, \mathrm{pH} 4.5)$.One hour after, all animals received oral D-glucose solution $(5 \%)$ to avoid hypoglycemic shock. Seventy-two hours (72 h) after induction, their blood glucose was taken at the tail vein using test strips and glucometer (One Touch Ultra Easy) for blood glucose testing. Rats with fasting glucose greater than or equal to $126 \mathrm{mg} / \mathrm{dL}$ were considered diabetic and used for the experiment (Miaffo et al., 2019).

\section{Distribution and treatment of animals}

Thirty (30) rats were randomly divided into 6 groups of 5 rats each. These rats received the various treatments for 28 days as follows:
Group 1 (normal control) received $10 \mathrm{~mL} / \mathrm{kg}$ bw of distilled water per os;

Group 2 (diabetic control) received $10 \mathrm{~mL} / \mathrm{kg}$ bw of distilled water per os;

Group 3 (standard control) received $3 \mathrm{mg} / \mathrm{kg}$ bw of the glibenclamide per os;

Groups 4, 5 and 6 received the extract at the respective doses of 125,250 , and $500 \mathrm{mg} / \mathrm{kg}$ bw per os.

Fasting blood glucose, body weight, food and water intake were assessed on days $0,7,14$, 21 , and 28 of treatment.

\section{Collection of blood and organs}

At the end of the treatment period, the animals were fasted for 24 hours with free access to water. Then they were anesthetized by an intraperitoneal injection of the combination of ketamine $(50 \mathrm{mg} / \mathrm{kg})$ and diazepam (10 $\mathrm{mg} / \mathrm{kg}$ ). The abdominal cavity was opened and blood was collected in tubes without anticoagulant and centrifuged at $3000 \mathrm{rpm}$ for $20 \mathrm{~min}$ at $4^{\circ} \mathrm{C}$. The supernatant obtained was taken and stored at $-20{ }^{\circ} \mathrm{C}$ for the assay of the biochemical parameters. After collecting the blood samples, the pancreas was removed and stored in $10 \%$ formalin for histological section.

\section{Assessment of biochemical parameters}

Blood glucose level was measured using a glucometer (One Touch Ultra Mini) and strips. Serum insulin was determined according to the enzyme-linked immuno-sorbent (ELISA) method using a commercial kit. Total cholesterol (TC), triglycerides (TG), high density lipoprotein cholesterol (HDL-c), low density lipoprotein cholesterol (LDL-c), malondialdehyde (MDA), glutathion (GSH), and superoxide dismutase (SOD) and catalase 
(CAT) activities were determined in serum using standard kits.

\section{Histological analysis of the pancreas}

Pancreas were fixed in $10 \%$ formalin and embedded in paraffin. The paraffin-embedded tissue specimens were sliced into $4 \mathrm{~mm}$ thickness sections, which were stained with hematoxylin and eosin (H\&E, 100x) and examined using a light microscope (Scientico STM-50).

\section{Statistical analysis}

All results were expressed as mean \pm SEM (Standard Error of Mean). Statistical analyses were evaluated by one-way ANOVA followed by Turkey posttest using Graph Pad Prism Software Version 5.0. Statistical significance was accepted at $\mathrm{p}<0.05$.

\section{Results and Discussion}

\section{Phytochemical screening}

Qualitative phytochemical analysis indicated the presence of flavonoids, saponins, phenols, tannins, terpenoids, glycosides, and anthraquinones and the absence of absence of alkaloids and steroids in the aqueous extract of T. dodoneifolius (Table 1).

\section{Body weight, food and water consumption}

Figure 1 shows the effects of the different treatments on the body weight (A), food consumption (B) and water intake (C) of rats treated with the aqueous extract of $T$. Dodoneifolius leaves for 28 days. It emerges from this figure that the body weight of the rats of the diabetic control group significantly decreased on days $14(\mathrm{p}<0.05), 21(\mathrm{p}<0.01)$, and $28(\mathrm{p}<0.001)$ of the treatment, in comparison with that of the normal control group. However, compared to the diabetic control group, a significant increase in body weight was observed in rats treated at the dose of $500 \mathrm{mg} / \mathrm{kg}$ of extract on days 21 ( p < 0.05) and $28(\mathrm{p}<0.01)$.Likewise, on day 28 of the experiment, body weight significantly increased $(\mathrm{p}<0.05)$ in animals receiving glibenclamide and the extract at the dose of $250 \mathrm{mg} / \mathrm{kg}$.

Rats in the diabetic control group exhibited significantly elevated food consumption on the 21st $(\mathrm{p}<0.05)$ and 28th $(\mathrm{p}<0.01)$ day of treatment, compared to the normal control group. Compared to untreated diabetic animals, rats given glibenclamide and doses of 125 and $250 \mathrm{mg} / \mathrm{kg}$ of extract showed no significant difference in food consumption throughout the treatment. In contrast, a significant decrease $(\mathrm{p}<0.05)$ in food consumption was noted in animals treated with the extract at a dose of $500 \mathrm{mg} / \mathrm{kg}$ at the last week of treatment (Figure 1).

Water consumption significantly increased in the diabetic control group rats on days 7 (p $<0.05), 14(\mathrm{p}<0.01), 21(\mathrm{p}<0.001)$ and $28(\mathrm{p}$ $<0.001$ ) of treatment, compared to that of the normal control group. Compared to the diabetic control group, on the 28th day of treatment, a significant decrease $(\mathrm{p}<0.01)$ in water consumption was noted with glibenclamide. Doses of 250 and $500 \mathrm{mg} / \mathrm{kg}$ of extract induced a significant decrease in water intake on days 14 ( $\mathrm{p}<0.05), 21$ ( $\mathrm{p}<0.01)$, and $28(\mathrm{p}<0.01)$ of treatment (Figure 1$).$

\section{Fasting blood glucose and fasting serum insulin}

On the first day of treatment, the blood glucose level of all animals receiving gliben clamide and $T$. dodoneifolius extract significantly ( $\mathrm{p}<0.001)$ increased, compared to the normal control group (Figure 2). During the 28 days of treatment, the blood glucose level of diabetic control group animals 
significantly $(p<0.001)$ remained high, compared with that of the rats of the normal control group. However, compared to the diabetic control group, the blood glucose level significantly decreased with glibenclamide ( $p$ $<0.01$ ) and the extract at doses of 250 (p < $0.05)$ and $500 \mathrm{mg} / \mathrm{kg}(\mathrm{p}<0.05)$ on day 7 of treatment. In addition, from the 14th to 28th day, glibenclamide and the different doses of the extract caused a significant $(\mathrm{p}<0.001)$ drop in blood glucose in the animals.

The effect of the aqueous extract of the leaves of $T$. dodoneifolius on the blood insulin level of diabetic rats shows a significant $(\mathrm{p}<0.001)$ decrease in insulinemia in untreated diabetic rats, compared to the normal control group (Figure 2).However, compared to the diabetic control group, the insulin level significantly increased in the animals receiving glibenclamide $(\mathrm{p}<0.01)$ and the extract at doses of $250(\mathrm{p}<0.05)$ and $500 \mathrm{mg} / \mathrm{kg}(\mathrm{p}<$ 0.05 ).Furthermore, no significant difference in insulin level was noted at the dose of 125 $\mathrm{mg} / \mathrm{kg}$ of extract.

\section{Lipid parameters}

Table 1 shows the effect of $T$. dodoneifolius extract on the lipid parameters of diabetic rats. In fact, the level of total cholesterol, triglycerides and LDL cholesterol significantly $(\mathrm{p}<0.001)$ increased in the animals of the diabetic control group, compared to the normal control group. On the other hand, the HDL cholesterol level significantly $(\mathrm{p}<0.05)$ decreased in the animals of the diabetic control group.

However, the extract at doses of 125 and 250 $\mathrm{mg} / \mathrm{kg}$ caused a significant decrease $(\mathrm{p}<0.05)$ in cholesterol level, compared to the diabetic control group. This decrease was greater $(\mathrm{p}<$ 0.001) with glibenclamide and the dose of 500 $\mathrm{mg} / \mathrm{kg}$ of extract (Table 2). A significant decrease $(\mathrm{p}<0.05)$ in triglyceride level was observed in animals given glibenclamide and the dose of $125 \mathrm{mg} / \mathrm{kg}$ extract. This decrease was greater $(p<0.01)$ with doses of 250 and $500 \mathrm{mg} / \mathrm{kg}$ of extract. Furthermore, glibenclamide and $T$. dodoneifolius extract at doses of 250 and $500 \mathrm{mg} / \mathrm{kg}$ resulted in a significant decrease $(\mathrm{p}<0.001)$ in LDL cholesterol level, compared to the diabetic control group. This decrease was less significant $(\mathrm{p}<0.05)$ with the dose of 125 $\mathrm{mg} / \mathrm{kg}$. In contrast, there was a significant increase $(\mathrm{p}<0.05)$ in HDL cholesterol level in rats treated with glibenclamide and the extract at doses of 250 and $500 \mathrm{mg} / \mathrm{kg}$. Furthermore, no significant difference in HDL cholesterol was noted at the dose of $125 \mathrm{mg} / \mathrm{kg}$ (Table 2).

\section{Oxidative stress parameters}

Table 3 shows the effect of the aqueous extract of the leaves of $T$. dodoneifolius on the level of MDA, GSH, and CAT and SOD activity in rats. It emerges from this study that the rats of the diabetic control group showed a significantly ( $\mathrm{p}<0.001)$ high level of MDA, and a significantly $(\mathrm{p}<0.001)$ low level of GSH and the activity of CAT and SOD, compared to the normal control group.

However, it was observed that the MDA level significantly decreased $(\mathrm{p}<0.001)$ in the rats receiving glibenclamide and the doses of 250 and $500 \mathrm{mg} / \mathrm{kg}$ of extract. Likewise, the dose of $125 \mathrm{mg} / \mathrm{kg}$ of extract induced a significant decrease $(p<0.01)$ in MDA level. In contrast, the rats treated with glibenclamide and the extract at doses of 250 and $500 \mathrm{mg} / \mathrm{kg}$ showed a significantly $\mathrm{p}<0.01$ ) elevated level of GSH, compared to the diabetic control group. The level of GSH did not change significantly in rats treated at the dose of 125 $\mathrm{mg} / \mathrm{kg}$ (Table 3). A significant increase in CAT activity was also noted with glibenclamide $(\mathrm{p}<0.05)$ and the extract at doses of $250(\mathrm{p}<0.05)$ and $500 \mathrm{mg} / \mathrm{kg}(\mathrm{p}<$ $0.01)$, compared to the diabetic control group. 
It was also noted that there is no significant difference in the activity of catalase between the animals receiving the dose of $125 \mathrm{mg} / \mathrm{kg}$ and those of the diabetic control group (Table 3). A significant increase $(\mathrm{p}<0.05)$ in SOD activity was observed in rats treated with glibenclamide and at doses of 125 and 250 $\mathrm{mg} / \mathrm{kg}$ of extract, compared to the diabetic control group. This increase was greater $(\mathrm{p}<$ 0.01 ) at the dose of $500 \mathrm{mg} / \mathrm{kg}$ of extract.

\section{Histological sections of pancreas tissue}

Figure 3 represents the histological section of the pancreas of diabetic rats. It emerges from this figure that the rats of the normal control group show a normal architecture of the pancreas (endocrine pancreas, welldifferentiated exocrine pancreas and welldeveloped pancreatic islands). On the other hand, in the rats of the diabetic control group, a reduction in the size of the islets of the pancreas was observed. Administration of the extract and glibenclamide prevented destruction of the islets of Langerhans in the pancreas.

Plants are important sources of chemical compounds, some of which can influence carbohydrate metabolism (Amiri et al., 2015).Certain secondary metabolites of plant origin have hypoglycaemic, lipid-lowering and antioxidant properties (Amiri et al., 2015). In the present work, phytochemical studies revealed the presence of chemical compounds such as polyphenols, tannins, saponins, flavonoids, triterpenes, glycosides, and anthraquinones in the aqueous extract of the leaves of $T$. dodoneifolis. Some of these compounds such as terpenoids, polyphenols, saponins, and flavonoids are known for their ability to lower blood sugar by inhibiting glucose transporters and the activity of alphaglucosidase enzymes (Fontana et al., 2011). Saponins also act as antihyperlipidemic, antioxidants, and cardioprotectors agents
(Hooper et al., 2008). The possible pharmacological effects obtained in the present study would be partly due to these bioactive molecules contained in the aqueous extract of T. dodoneifolius leaves.

One of the main characteristics of type 1 diabetes is severe loss of body mass (Oliveira et al., 2013). In the present study, significant loss of body weight was noted in untreated diabetic rats. This drastic weight loss is probably due to an insulin deficiency which leads to a decrease in the absorption of amino acids by the tissues with a consequent reduction in protein synthesis. Moreover, numerous studies suggest that the loss of body weight in diabetics can be explained by an increase in lipid and protein catabolism due to carbohydrate deficiency (Sathishsekar and Subramanian, 2005). In contrast, in the treated diabetic groups, administration by gavage of glibenclamide and the aqueous extract at daily doses of 250 and $500 \mathrm{mg} / \mathrm{kg}$ for 4 weeks resulted in an increase in the body weight of the animals. The ability of the extract to protect diabetic rats from weight loss appears to be due to its ability to lower blood sugar as well as its protective effect on protein turnover and / or amelioration of disorders associated with diabetes mellitus (Balamurugan et al., 2014).

Polyphagia and polydipsia are symptoms of diabetes mellitus that are caused by insulin deficiency or lack of insulin use by target organs. These parameters essentially inform us about the reestablishment of insulin secretion as well as the degree of glucose utilization by the cells Rodríguez et al., 1997). In the present study, a significant increase in food and water intake was noted in untreated diabetic animals. The exaggeration of food consumption indicates that the body cannot use glucose, although it is abundantly provided that it draws on its reserves of lipids and proteins for its energy metabolism (Sami et al., 2017). The 
increased water intake in diabetics is caused by high blood sugar overflowing into the urine resulting in dehydration. In contrast, administration of glibenclamide and $T$. dodoneifolius extract at doses of 250 and / or $500 \mathrm{mg} / \mathrm{kg}$ resulted in reduced food and water consumption in diabetic rats. The decrease in food and water intake in the groups treated with the extract could be due to the drop in blood sugar observed in these groups, which could indicate the insulinomimetic or insulinsecreting action of the extract of $T$. dodoneifolius (Muniappan et al., 2014).

The two pathophysiologies of diabetes mellitus are insulin deficiency and insulin resistance. The administration of streptozotocin causes partial destruction of pancreatic $\beta$ cells and therefore a decrease in serum insulin level. In fact, diabetogenic agents have a pathological effect interfering with the physiological function of the $\beta$ cells of the pancreas; they lead to selective destruction of these cells, thus inducing chronic hyperglycemia (Szkudelski, 2001).

The present study indicates that oral administration of the extract at doses of 250 and $500 \mathrm{mg} / \mathrm{kg}$ to diabetic rats resulted in a significant decrease in blood glucose level, and an increase in insulin level as did glibenclamide. These results are attributable to the chemical compounds (flavonoids, phenols, and glycosides) present in the extract, which have the ability to mimic the action of insulin or to stimulate its secretion by the $\beta$ cells of the islets of Langerhans (Tanko et al., 2008; Khurshid Alam et al., 2018). Another possible mechanism of action of the extract is the regeneration of pancreatic $\beta$ cells. This is further confirmed by the results of histological sections of the pancreas which showed an increase in the number and size of the islets of Langerhans after administration of the aqueous extract of the leaves of $T$. dodoneifolius.
Diabetes mellitus is also associated with hyperlipidemia which causes profound disturbances in the concentration and composition of lipids and lipoproteins.

These abnormalities represent an important risk factor for cardiovascular disease (Woo et al., 2008). Hyperlipidemia is a recognized complication of diabetes mellitus characterized by high concentrations of TC, $\mathrm{TG}$, and phospholipids and changes in the composition of the lipoprotein (Raviet al., 2005). In the present study, a significant increase in TC, TG and LDL-c was observed, and a significant decrease in HDL-c in diabetic animals. In contrast, in animals treated with glibenclamide and extract of $T$. dodoneifolius (125, 250, and $500 \mathrm{mg} / \mathrm{kg}$ ), a significant decrease in the level of $\mathrm{TC}, \mathrm{TG}$, and LDL-cand an increase HDL-c level was observed, compared to diabetic control groups.

These results are similar to those obtained by Miaffo et al., (2014) with Combretum molle. The extract of $T$. dodoneifolius is said to have either mimicked the action of insulin in adipose tissue or to stimulate its secretion in the pancreas. It probably works by decreasing the biosynthesis of cholesterol specifically by decreasing the activity of the enzyme 3hydroxy-3-methyl-glutaryl coenzyme A reductase (HMG-CoA reductase). In addition, the extract would have reduced the level of serum triglycerides by decreasing the synthesis of fatty acids, increasing the catabolism of LDL and producing triglyceride precursors such as acetyl-CoA and glycerol phosphate (Eddouks et al., 2005). Limaye et al., (2003) have shown that secondary metabolites such as flavonoids, saponins, and phenols have lipid-lowering activity. The observed antidyslipidemic effect could be due to the presence of these classes of chemical compounds in the aqueous extract of the leaves of $T$. dodoneifolius. 
Table.1 Chemical compounds present in the aqueous extract of the leaves of Tapinanthus dodoneifolius

\begin{tabular}{|c|c|}
\hline Chemical compounds & Extract \\
\hline Flavonoids & + \\
\hline Phenols & + \\
\hline Tannins & + \\
\hline Saponins & + \\
\hline Alkaloids & - \\
\hline Terpenoids & + \\
\hline Glycosides & + \\
\hline Steroids & - \\
\hline Anthraquinones & + \\
\hline
\end{tabular}

Table.2 Effects of aqueous extract of $T$. dodoneifolius leaves on lipid parameters in rats

\begin{tabular}{|c|c|c|c|c|c|}
\hline Groups & $\begin{array}{c}\text { Dose } \\
(\mathbf{m g} / \mathbf{k g})\end{array}$ & $\begin{array}{c}\mathbf{C T} \\
(\mathbf{m g} / \mathbf{d L})\end{array}$ & $\begin{array}{c}\text { TG } \\
(\mathbf{m g} / \mathbf{d L})\end{array}$ & $\begin{array}{c}\text { HDL-c } \\
(\mathbf{m g} / \mathbf{d L})\end{array}$ & $\begin{array}{c}\text { LDL-c } \\
(\mathbf{m g} / \mathbf{d L})\end{array}$ \\
\hline Normal control & - & $89.78 \pm 4.37$ & $78.37 \pm 5.76$ & $38.22 \pm 2.39$ & $55.89 \pm 2.28$ \\
\hline Diabetic control & - & $133.64 \pm 6.24 * * *$ & $113.27 \pm 5.54^{* * *}$ & $23.35 \pm 0.64^{*}$ & $104.64 \pm 6.15^{* * *}$ \\
\hline Glibenclamide & 10 & $100.20 \pm 4.77 \mathrm{c}$ & $84.39 \pm 7.06 \mathrm{a}$ & $28.52 \pm 1.20$ & $69.80 \pm 4.43 \mathrm{c}$ \\
\hline Extract & 125 & $110.62 \pm 3.63 \mathrm{a}$ & $86.94 \pm 5.25 \mathrm{a}$ & $30.87 \pm 1.01 \mathrm{a}$ & $82.35 \pm 4.37 \mathrm{a}$ \\
& 250 & $108.553 .64 \mathrm{a}$ & $81.63 \pm 5.08 \mathrm{~b}$ & $33.69 \pm 1.35 \mathrm{a}$ & $27.71 \pm 5.85 \mathrm{c}$ \\
& 500 & $91.67 \pm 5.29 \mathrm{c}$ & $79.62 \pm 4.46 \mathrm{~b}$ & $35.26 \pm 1.20 \mathrm{a}$ & $13.77 \pm 1.10 \mathrm{c}$ \\
\hline
\end{tabular}

Each value represents the mean \pm SEM $; n=5 . * * p<0.01 ; * * * p<0.001$ statistically significant difference from the normal control group. ap $<0.05 ; \mathrm{bp}<0.01 ; \mathrm{cp}<0.001$ statistically significant compared to the diabetic control. CT: total cholesterol, TG: triglycerides, HDL-c: High density lipoprotein cholesterol, LDL-c: Low density lipoprotein cholesterol. 
Table.3 Effects of aqueous extract of $T$. dodoneifolius leaves on antioxidant parameters in rats

\begin{tabular}{|c|c|c|c|c|c|}
\hline Groups & $\begin{array}{c}\text { Dose } \\
(\mathrm{mg} / \mathrm{kg})\end{array}$ & $\begin{array}{c}\text { MDA } \\
(\mathbf{m g} / \mathbf{d L})\end{array}$ & $\begin{array}{c}\text { GSH } \\
(\mathbf{m g} / \mathbf{d L})\end{array}$ & $\begin{array}{c}\text { CAT } \\
(\mathbf{m g} / \mathbf{d L})\end{array}$ & $\begin{array}{c}\text { SOD } \\
(\mathbf{m g} / \mathbf{d L})\end{array}$ \\
\hline Normal control & - & $7.54 \pm 0.59$ & $11.54 \pm 1.12$ & $15.56 \pm 1.34$ & $21.70 \pm 2.11$ \\
\hline Diabetic control & - & $17.82 \pm 1.59 * * *$ & $5.46 \pm 0.75^{* *}$ & $6.42 \pm 0.82 * * *$ & $9.98 \pm 0.92 * * *$ \\
\hline Glibenclamide & 3 & $9.96 \pm 0.83 c$ & $9.96 \pm 0.73 a$ & $13.26 \pm 1.40 \mathrm{a}$ & $16.61 \pm 1.99 a$ \\
\hline Extract & $\begin{array}{l}125 \\
250 \\
500\end{array}$ & $\begin{array}{c}11.36 \pm 1.37 b \\
9.61 \pm 1.04 c \\
8.50 \pm 0.68 c\end{array}$ & $\begin{array}{c}7.06 \pm 0.84 \\
10.66 \pm 1.27 \mathrm{a} \\
10.28 \pm 1.18 \mathrm{a}\end{array}$ & $\begin{array}{c}9.92 \pm 0.89 \\
12.52 \pm 1.07 \mathrm{a} \\
14.90 \pm 1.50 \mathrm{~b}\end{array}$ & $\begin{array}{l}17.26 \pm 0.52 a \\
16.28 \pm 0.60 a \\
18.36 \pm 1.04 b\end{array}$ \\
\hline
\end{tabular}

Each value represents the mean $\pm \mathrm{SEM} ; \mathrm{n}=5 . * * \mathrm{p}<0.01 ; * * * \mathrm{p}<0.001$ statistically significant difference from the normal control group. ap $<0.05 ; \mathrm{bp}<0.01 ; \mathrm{cp}<0.001$ statistically significant compared to the diabetic control MDA : malondialdehyde, SOD : superoxyde dismutase, CAT : catalase, GSH :reduced glutathion.

Fig.1

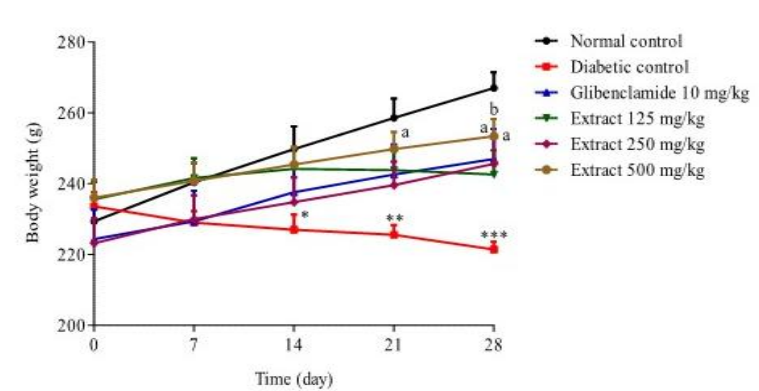

A

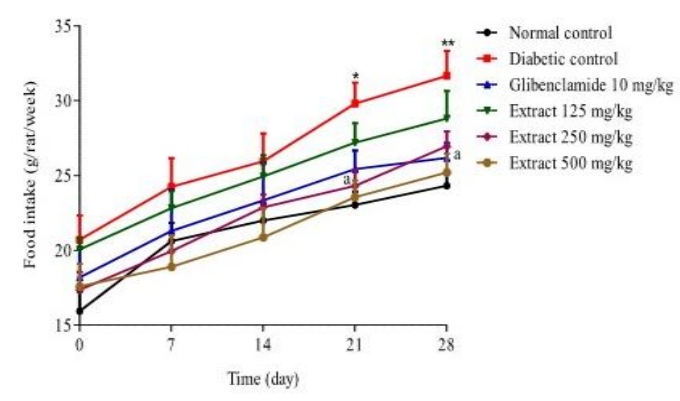

B

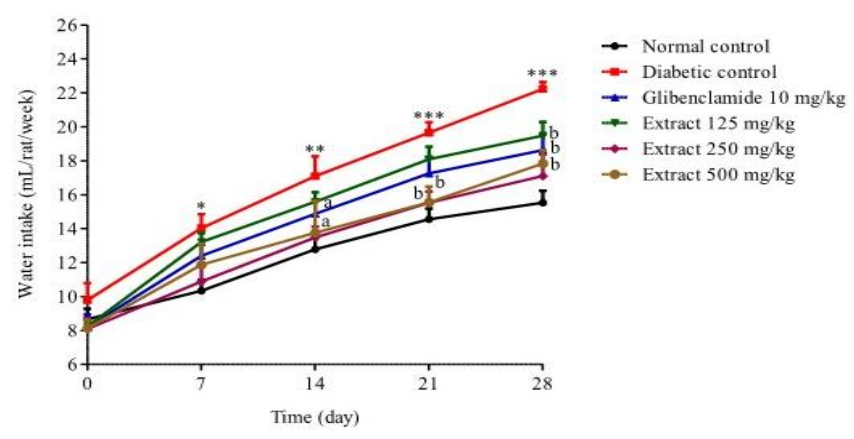

C

Fig.1 Effects of aqueous extract of $T$. dodoneifolius leaves on body weight (A), food consumption (B), and water intake (C) in animals. Each value represents mean $\pm S E M, n=5$. Data analysis was performed by two-way ANOVA followed by Bonferroni's post-hoc test. *P $<0.05 ; * * \mathrm{P}<0.01 ; * * * \mathrm{P}<0.001$ compared to the normal control. ap $<0.05 ;$ bp $<0.01$ compared to the diabetic control. 
Fig.2

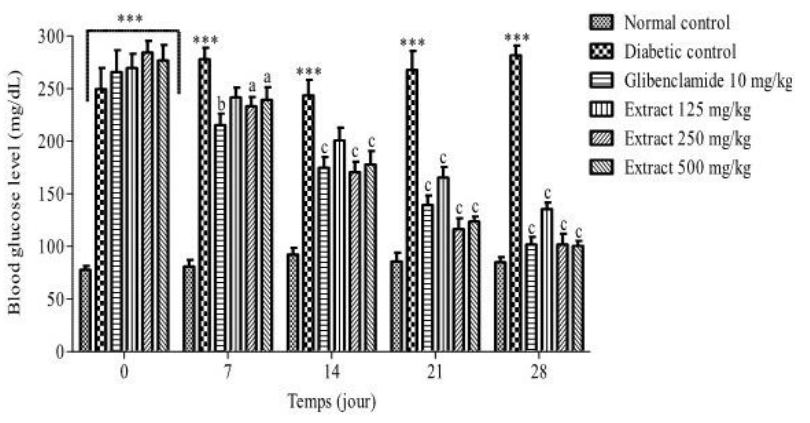

A

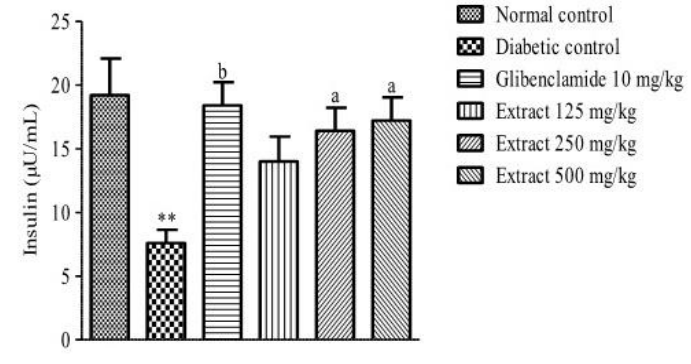

B

Fig.2 Effects of aqueous extract of $T$. dodoneifolius leaves on blood glucose level (A) and insulin level (B) in rats. Each value represents mean $\pm S E M, n=5$. Data analysis was performed by two-way ANOVA followed by Bonferroni's post-hoc test. ${ }^{* *}$ p $<0.001 ; * * p<0.01$ compared to the normal control. ap $<0.05$; bp $<0.01 ; \mathrm{cp}<0.001$ compared to the diabetic control.

Fig.3

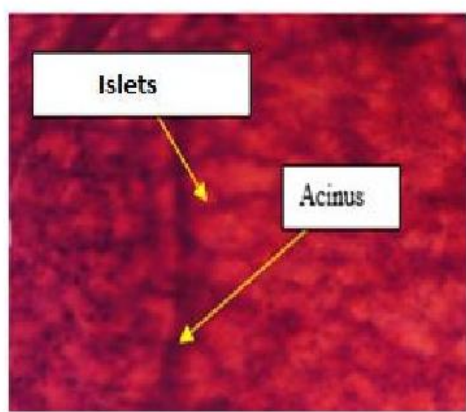

Normal control

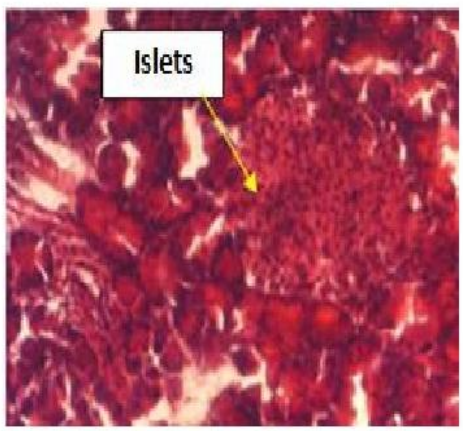

Extract $125 \mathrm{mg} / \mathrm{kg}$

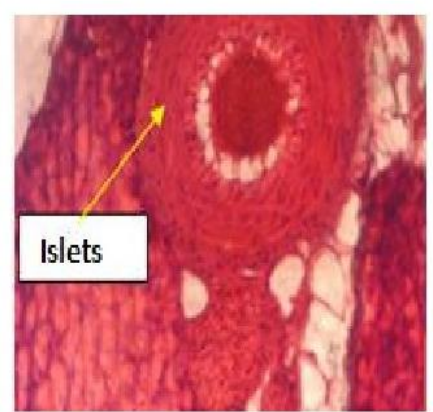

Diabetic control

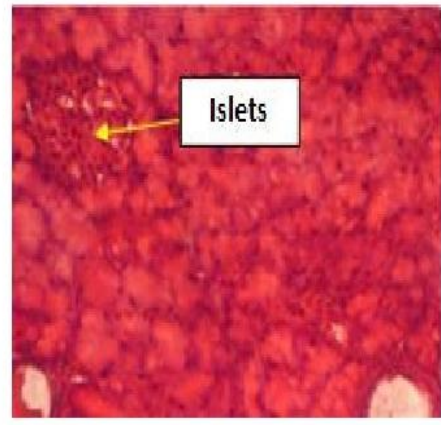

Extract $250 \mathrm{mg} / \mathrm{kg}$

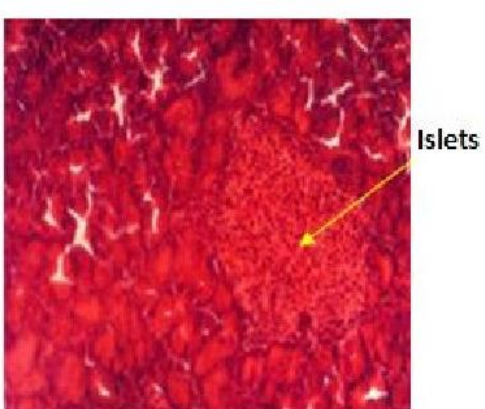

Glibenclamide

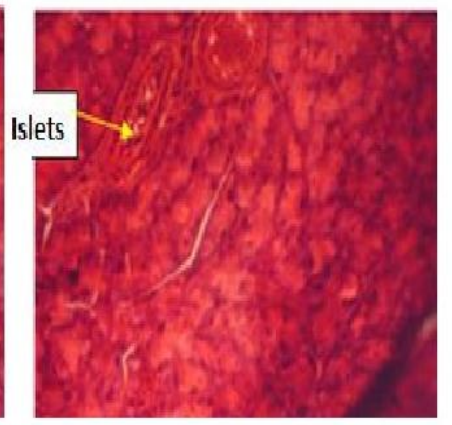

Extract $500 \mathrm{mg} / \mathrm{kg}$

Fig.3 Effects of of aqueous extract of $T$. dodoneifolius leaves on pancreas histology. 
Several studies have shown that oxidative stress plays an important role in the progressive development of diabetes and its complications (Kumar et al., 2004). In the diabetic state, free radical generation can occur via increased glycolysis, intercellular activation of the polyol pathway, autooxidation of glucose, and glycation of nonenzymatic proteins (Sharma et al., (2008). We noticed an increase in the level of MDA, and a decrease in the activity of antioxidant enzymes (CAT and SOD) and the concentration of GSH in diabetic rats. However, glibenclamide and / or the aqueous extract of $T$. dodoneifolius caused a decrease in the level of MDA and an increase in the activity of CAT, SOD, and the level of GSH. These results are similar to those of Webo et al., (2019) and Mahamad et al., (2020) with Baillonella toxisperma and Cissus polyantha, respectively. The extract is said to have prevented oxidative damage by scavenging and scavenging free radicals in order to restore the antioxidant parameters disrupted by streptozotocin. According to Patel et al., (2014)and Abdelaziz et al.,(2015), phenols and flavonoids possess the antioxidant potential via their reducing power or their potential for donating or transferring electrons or hydrogen.

The oral administration of aqueous extract of T. dodoneifoliusleaves in rats possess the hypoglycaemic and hypolipidemic effects, and protect tissues against damage induced by oxidative stress. These different pharmacological properties are thought to be due to the phytoconstituents presents in the extract. This study provides evidence for the ethnobotanical use of $T$. dodoneifolius extract as a treatment for diabetes mellitus.

To complete this work, more in-depth and detailed studies will be performed later to isolate and identify the main active compounds and their mechanisms of action.

\section{Acknowledgments}

The authors are grateful to the Laboratory of Department of Biological Science, Faculty of Sciences, University of Maroua (Cameroon) and the Laboratory of Life and Earth Sciences of the University of Maroua (Cameroon) for providing the facility to carryout the research.

\section{References}

American Diabetes Association. Diagnosis and classificationof diabetes mellitus. Diabetes Care. 2010;33(1):62 - 9.

International Diabetes Federation. Diabetes atlas. ninth ed. Brussels, Belgium. 2019.

Standards of Medical Care in Diabetes-2016. Summary of revisions. Diabetes Care. 2016;39(1):4-5.

Nasri H, Rafieian-Kopaei M. Protective effects of herbal antioxidants on diabetic kidney disease. Journal of Research in Medical Sciences. 2014;19:82-83.

Efuntoye M.O, Ayodele A.E, Thomas B.T, Ajayi T.O. Does host plant affect the antibacterial activity of Tapinanthus bangwensis (Engl. and K. Krause) Danser (Loranthaceae)? Journal of Medicinal Plant Research. 2010;4:1281-1284.

Ekhaise O. F, Agboh M. K, Uanseoje S. Evaluation of the methanolic extract of Mistletoe (Tapinanthus bangwensis) leaves grown on orange trees for the phytochemical properties and its physiological effect on streptozotosin induced diabetes mellitus in laboratory animals. WorldAppliedSciences Journal. 2010;9:975-979.

Baso A. A, Mudi S. Y. Evaluation of antiulcer and phytochemical activities of leaf extracts from Tapinanthus dodoneifolius DC. (Loranthaceae) grown on Tamarindus indica tree. Bayero Journal of Pure and Applied Sciences. 2017;10:392-396.

Deeni Y, Sadiq N. Antimicrobial properties and phytochemical constituents of the leaves of African mistletoe (Tapinanthus dodoneifolius (DC) Danser) 
(Loranthaceae): An ethnomedicinal plant of Hausaland, Northern Nigeria. Journal of Ethnopharmacology. 2002;83:235-240.

Pandey A, Tripathi S. Concept of standardization, extraction and prephytochemical screening strategies for herbal drug. Journal of Pharmacognosy and Phytochemistry.2014;2:115-119.

Miaffo D, Guessom Kamgue O, Ledang Tebou N, Maa Maa Temhoul C, Kamanyi A. Antidiabetic and antioxidant potentials of Vitellaria paradoxa barks in alloxaninduceddiabetic rats. Clinical Phytoscience. 2019;5:44.

Amiri A, Azemi M. E, Khodayar M. J, Namjoyan F. In vitro $\alpha$-amylase and $\alpha$ glucosidases inhibitory effects of some plant extracts", International Journal of Pharmacognosy and Phytochemical Research, 2015;7:315-318.

Fontana Pereira D, Cazarolli L H, Lavado C et $a l$., Effects of flavonoids on $\alpha$-glucosidase activity: Potential targets for glucose homeostasis. The Journal of Nutrition. 2011;27:1161-1167.

Hooper L, Kroon P A, Rimm E B et al., Flavonoids, flavonoid-rich foods, and cardiovascular risk: A meta-analysis of randomized controlled trials. The American Journal of Clinical Nutrition. 2008;88:38-50.

Oliveira G. O, Braga C. P, Fernandes, A. A. H. Improvement of biochemical parameters in type 1 diabetic rats after the roots aqueous extract of yacon [Smallanthus sonchifolius (Poepp.\&Endl.)] treatment. Food and Chemical Toxicology. 2013;59:256-260.

Sathishsekar D, Subramanian S. Antioxidant properties of Momordica Charantia (bitter gourd) seeds on streptozotocin induced diabetic rats. Asiatic Journal Clinic and Nutrition. 2005;14 (2):153158.

Balamurugan K, Nishanthini A, Mohan V. R. Antidiabetic and antihyperlipidaemic activity of ethanol extract of Melastoma malabathricum Linn. Leaf in alloxan induced diabetic rats. Asian Pacific Journal of Tropical Biomedicine. 2014;4(1):442-448.

Rodríguez T, Alvarez B, Busquets S, Carbó N, López-Soriano F.J, Argilés J.M.The increased skeletal muscle protein turnover of the streptozotozin diabetic rat is associated with high concentrations of branched-chain amino acids. Biochemical and Molecular Medicine. 1997;61(1):8794.

Sami W, Ansari T, Butt N. S, Hamid M. R. A. Effect of diet on type 2 diabetes mellitus: A review. International Journal of Health Sciences. 2017;11(2):65-71.

Muniappan L, Leelavinothan P, Sandhya S, Ramesh B. Insulin-secretagogue activity and cytoprotective role of the traditional antidiabetic plant Scoparia dulcis (Sweet Broomweed). Life Science.2004;75:20032014.

Szkudelski T. The Mechanism of Alloxan and Streptozotocin Action in B Cells of the Rat Pancreas. Physiological Reseach. 2001;50:536-546.

Tanko Y, Yerima M, Mahdi M. A, Yaro A. H, Musa K. Y, Mohammed A. Hypoglycemic activity of methanolic stem bark of Adansonnia digitata extract on blood glucose levels of STZ-induced Wistar rats. International Journal of Applied Research in Natural Products. 2008;1(2):32-6.

Khurshid Alam A. H. M, Sharmin R, Maruf I, Hasibul Hasan J, Mohiuddin A, Golam M. Antidiabetic and hepatoprotective activities of Bombax ceiba young roots inalloxan-induced diabetic mice. International Journal of Nutrition and Food Sciences. 2018;6(5):1-7.

Woo M. N, Bok S. H, Lee M. K, Kim H. J, Jeon S. M, Do G. M, Shin S. K, Ha T. Y, Choi M. S. Anti-obesity and hypolipidemic effects of a proprietary herb and fiber combination (S\&S PWH) in rats fed high fat diets. Journal of Medicinal Food. 2008;11:169-178.

24.RaviK, Rajasekaran S, Subramanian S. Antihyperlipidemia effect of Eugenia 
Jambolana seed kernel on streptozotocin induced diabetes in rats. Food and Chemical Toxicology. 2005;43(9):143339.

Miaffo D, Kamani Poualeu S. L, Kamanyi A. Antidiabetic activity of the methanol and acetone extracts of twigs of Combretum molle in dexamethasone induced-insulin resistance in rats. World journal of Pharmaceutical Sciences. 2014;2(9):955965.

Eddouks M, Maghrani M, Zeggwagh N. A, Michel J. B. Study of the hypoglycaemic activity of Lepidium sativum L. aqueous extract in normal and diabetic rats. Journal of Ethnopharmacology. 2005;97:391-395.

Limaye P V, Raghuram N, Sivakami S. Oxidative stress and gene ion of antioxidant enzymes in the renal cortex of streptozotocin induced diabetic rats. Molecular and Cellular Biology. 2003;243(1/2):147-52.

Kumar G, Sharmila B, Vanitha P.P, Sundararajan M, Rajasekara P. M. Hepatoprotective activity of Trianthema portulacastrum L. against paracetamol and thioacetamide intoxication in albino rats. Journal of Ethnopharmacology. 2004;92(1):37-40.

Sharma B., Viswanath G., Salunke R, Roy P.
Effects of flavonoid rich extract from seeds of Eugenia jambolana (L.) on carbohydrate and lipid metabolism in diabetic mice. Food Chemistry. 2008;110:697-705.

Wego M. T, Poualeu Kamani S. L, Miaffo D, Nchouwet M. L, Kamanyi A, Wansi Ngnokam S. L. Protective effects of aqueous extract of Baillonella toxispermastem bark on dexamethasoneinduced insulin resistance in rats. Advances in Pharmacological and Pharmaceutical Sciences. 2019;2019:6.

Mahamad A T, Miaffo D, Poualeu Kamani S L et al., Glucose, lipid and oxidative stress lowering activity of the aqueous extract from leafy stems of Cissus polyantha Gilg $\&$ Brandt in dexamethasone-induced hyperglycemia in rats. Journal of Diabetes and Metabolic Disorders.2020;2020:11.

Patel J. J, Acharya S. R, Acharya N. S. Clerodendrum serratum (L.) Moon. a review on traditional uses, phytochemistry and pharmacological activities. Journal of Ethnopharmacology.2014;154(2):268-85.

Abdelaziz D. H, Ali S. A, Mostafa M. M. Phoenix dactylifera seeds ameliorate early diabetic complications in streptozotocininduced diabetic rats. Pharmaceutical Biology 2015; 53(6):792-799.

\section{How to cite this article:}

Kopodjing Bello Angèle, Ntchapda Fidèle and Miaffo David. 2021. Type 1 diabetes mellitus: therapeutic correction trial with the aqueous extract of the leaves of Tapinanthus dodoneifolius (Loranthaceae). Int.J.Curr.Microbiol.App.Sci. 10(07): 697-709. doi: https://doi.org/10.20546/ijcmas.2021.1007.076 